\title{
The Debt to GDP Ratio When Not All Savings Is Used for Consumption
}

\author{
Yasuhito Tanaka \\ Faculty of Economics, Doshisha University \\ Kamigyo-ku, Kyoto, 602-8580, Japan \\ Tel: 81-75-251-36248Ｅ-mail: ochibocho@gmail.com
}

Received: January 1, 2022

Accepted: January 23, 2022

Published: February 25, 2022

doi:10.5296/iss.v8i2.19426

URL: http://dx.doi.org/10.5296/iss.v8i2.19426

\begin{abstract}
One of the most commonly used conditions for examining fiscal stability is the Domar condition. It compares the interest rate with the economic growth rate under balanced budget (excluding interest payments), and if the former is greater than the latter, public finances will become unstable, and the outstanding government debt will continue to grow. In this note we consider a problem of the debt to GDP ratio when not all savings of consumers of a generation is not used for consumption by consumers of the next generation using a simple macroeconomic model without complicated microeconomic foundation. If not all savings of consumers is not used for consumption, demand is insufficient, and we need larger budget deficit to maintain full employment in a growing economy. However, we show that fiscal instability or un-sustainability do not occur even if not all savings is used for consumption, and the interest rate exceeds the growth rate.
\end{abstract}

Keywords: Domar condition, Budget deficit, Debt to GDP ratio

JEL classification: E12, E24. 


\section{Ml Macrothink}

\section{Introduction}

One of the most commonly used conditions for examining fiscal stability is the Domar condition (Domar (1944)). We refer to Yoshino and Miyamoto (2020). The Domar condition compares the interest rate with the economic growth rate under balanced budget (excluding interest payments on the government bonds), and if the former is greater than the latter, public finance will become unstable, and the outstanding government debt will continue to grow.

Yoshino and Miyamoto (2020) try to modify the Domar condition by focusing not only on the supply side of government bonds but also on the demand side, while keeping the idea of fiscal instability indicated by the Domar condition. However, our interest is different from that. We consider a problem of the debt to GDP ratio when not all savings by consumers of a generation is not used for consumption by consumers of the next generation using a simple macroeconomic model without complicated microeconomic foundation. If not all savings is used for consumption, demand is insufficient, and we need larger budget deficit to achieve and maintain full employment in a growing economy. However, we show that fiscal instability or un-sustainability do not occur even if not all savings is used for consumption, and the interest rate exceeds the growth rate (Note 1).

Let

$\delta$ : proportion of savings that is used for consumption, $0<\delta \leqq 1$,

$r$ : interest rate of government bond.

We define

$\rho$ : effective interest rate, $\rho=(1+r) \delta-1$,

We will show the following results.

1). In order to maintain full employment under economic growth with constant price, the budget deficit, including interest payments on government bonds, must be positive. (Proposition 1)

2 ). If the effective interest rate is larger than the growth rate, in order to maintain full employment under economic growth with constant price, the budget deficit, excluding interest payments on government bonds, must be negative (budget surplus). (Proposition 2)

3). Under full employment with constant price the debt to GDP ratio converges to a finite value so long as the growth rate is positive. (Proposition 3)

4). The excessive budget deficit causes inflation. (Proposition 4)

5). When inflation is predicted, we need positive budget deficit (excluding interest payments) to maintain full employment under economic growth even if the effective interest rate is larger than the real growth rate, so long as it is smaller than the nominal growth rate. (Proposition 5) 


\section{I Macrothink}

6). Under full employment with continued inflation the debt to GDP ratio converges to a finite value so long as the nominal growth rate is positive. (Proposition 6)

7). Under the balanced budget with inflation the effective interest rate equals the nominal growth rate, and the debt to GDP ratio does not increase even if the effective interest rate is larger than the real growth rate. (Proposition 7)

8). The budget deficit, including interest payments on government bonds, equals the difference between the savings of consumers in a period and the effective savings, which will be defined in Section 2.1, in the previous period. (Proposition 8)

9). The result in Proposition 8 holds whether we have full employment or not, whether we have inflation or not.

In Appendix we consider the debt-to-GDP ratio about budget deficit due to unused savings and the role of inheritance tax to prevent the debt-to-GDP ratio from diverging indefinitely.

Since we consider a long-run problem of the debt to GDP ratio, full employment is assumed.

\section{Economic Growth under Full Employment With Constant Price and the Debt to GDP Ratio}

\subsection{Economic Growth under Full Employment with Constant Price}

We consider a simple macroeconomic model without microeconomic foundation of consumers and firms (Note 2). We assume that the economy grows between periods (or generations) at the rate of $\gamma-1>0$. Let $Y_{f}$ be the full employment real national income in Period 1. The full employment real national income increases from a period to the next period at the rate of $\gamma-1>0$. The price of goods in Period 1 is one. The issue of inflation will be considered in the next section. The consumption function in this period under full employment is

$$
C=C_{0}+\alpha\left(Y_{f}-T\right)
$$

$C$ is the real consumption. $C_{0}$ is the constant part of $C . T$ is the tax. $\alpha$ is the marginal propensity to consume. $0<\alpha<1$. The national income in this period satisfies the following equation.

$$
Y_{f}=C+I+G=C_{0}+\alpha\left(Y_{f}-T\right)+I+G
$$

$G$ is the real government expenditure. $I$ is an investment of firms. No detailed analysis of investment is given. The savings of the consumers in this period is

$$
(1-\alpha)\left(Y_{f}-T\right)-I
$$

We suppose that the savings is made not in money but in government bonds, which generate interest at the rate of $r$. We write 


$$
B=(1-\alpha)\left(Y_{f}-T\right)-I
$$

We assume that $C_{0}$ is financed by the savings by the previous generation consumers. However, not all savings is used for consumption. Thus, there will be a shortage of demand and a larger budget deficit will be needed to achieve full employment. We will denote by $\delta$ $(0<\delta \leqq 1)$ the proportion of savings that is used for consumption. The rest is simply left unused. If interest continues to be paid on savings that are not used for consumption, the ratio of their sum to GDP may diverge to infinity. In such a case, it shall be offset by an inheritance tax. Please see Appendix.

Define the effective interest rate by

$$
\rho=(1+r) \delta-1
$$

and the effective savings by

$$
(1+\rho-r)\left[(1-\alpha)\left(Y_{f}-T\right)-I\right]=(1+\rho-r) B
$$

Then,

$$
C_{0}=\frac{1+r}{\gamma} \delta\left[(1-\alpha)\left(Y_{f}-T\right)-I\right]=\frac{1+\rho}{\gamma}\left[(1-\alpha)\left(Y_{f}-T\right)-I\right]=\frac{1+\rho}{\gamma} B
$$

Investment and tax also increase at the rate of $\gamma-1$. If $\delta<1$, we have $\rho<r$. From (1)

$$
G-T=\frac{\gamma-(1+r) \delta}{\gamma}\left[(1-\alpha)\left(Y_{f}-T\right)-I\right]=\frac{\gamma-1-\rho}{\gamma} B .
$$

Since $\gamma-1>0, r-\rho>0$, and

$$
\gamma-1+r-\rho>0
$$

(2) is rewritten as

$$
G-T+\frac{r}{\gamma} B=\frac{\gamma-1+r-\rho}{\gamma} B>0
$$

The left-hand side is the budget deficit, including interest payments on government bonds. If the budget deficit is smaller than this level, full employment is not achieved. Therefore, we get the following result.

Proposition 1: In order to maintain full employment under economic growth with constant price, the budget deficit, including interest payments on government bonds, must be positive.

In fact, we need budget deficit even if $\gamma=1$ (zero growth rate) when $\delta<1$.

\subsection{When the Effective Interest Rate Is Larger than the Growth Rate}

If the effective interest rate $\rho$ is larger than the growth rate $\gamma-1$, then (2) is negative. This means that if the effective interest rate is larger than $\gamma-1$, the budget deficit, excluding 


\section{Macrothink}

interest payments on government bonds, must be negative, that is, we need budget surplus (excluding interest payments).

Proposition 2: If the effective interest rate is larger than the growth rate, $\rho>\gamma-1$, in order to maintain full employment under economic growth with constant price, the budget deficit, excluding interest payments on government bonds, must be negative (budget surplus).

This proposition implies that the balanced budget (excluding interest payments on government bonds) does not satisfy (2) if $\rho>\gamma-1$. For details, please see Section 2.4. Note that if $\delta=1$, that is, all savings is used for consumption, $\rho=r$.

\subsection{Debt to GDP Ratio under Constant Price}

Now consider the long-run value of the debt to GDP ratio. We assume that full employment continues to be maintained under constant price. The economy begins in Period 0. In that period, we have $C_{0}=0$, and the budget deficit is

$$
\frac{1}{\gamma}(G-T)=\frac{1}{\gamma}\left[(1-\alpha)\left(Y_{f}-T\right)-I\right]=\frac{1}{\gamma} B
$$

Note that $B$ is the government debt in Period 1. In Period 1

$$
G-T+\frac{r}{\gamma} B=\frac{\gamma+r-1-\rho}{\gamma} B
$$

Then, in Period 2 we have

$$
\gamma(G-T)+r B=(\gamma+r-1-\rho) B .
$$

Generally, in Period $n$ the budget deficit is

$$
\gamma^{n-1}(G-T)+r \gamma^{n-2} B=\gamma^{n-2}(\gamma+r-1-\rho) B .
$$

Note that $G$ and $T$ denote the fiscal spending and the tax in Period 1. The sum of the budget deficit from Period 0 to $n$ is calculated by

$$
\sum_{k=1}^{n} \gamma^{k-2}(\gamma+r-1-\rho) B+\frac{1}{\gamma} B=\left(\frac{\gamma^{n}-1}{\gamma-1}\right)\left(\frac{\gamma+r-1-\rho}{\gamma}\right) B+\frac{1}{\gamma} B
$$

Since the national income in Period $n$ is $\gamma^{n-1} Y_{f}$, the debt to GDP ratio in that period is

$$
\frac{\left(\frac{\gamma^{n}-1}{\gamma-1}\right)\left(\frac{\gamma+r-1-\rho}{\gamma}\right) B+\frac{1}{\gamma} B}{\gamma^{n-1} Y_{f}} .
$$

When $n \rightarrow \infty$, so long as $\gamma-1>0$, that is, the growth rate is positive, it converges to

$$
\left(\frac{\gamma+r-1-\rho}{\gamma-1}\right) \frac{B}{Y_{f}}=\left(\frac{\gamma+r-1-\rho}{\gamma-1}\right)\left[\frac{(1-\alpha)\left(Y_{f}-T\right)-I}{Y_{f}}\right] .
$$

This has a finite value. We have shown the following result.

Proposition 3: Under full employment with constant price the debt to GDP ratio converges 


\section{Macrothink}

to a finite value so long as the growth rate, $\gamma-1$, is positive.

Note that this proposition does not depend on the relationship between the interest rate (or the

effective interest rate) and the growth rate. They are included in $\frac{\gamma+r-1-\rho}{\gamma-1}$. However, it is finite when $\gamma-1>0$.

\subsection{Balanced Budget Under Constant Price When the Effective Interest Rate Is Larger than} the Growth Rate and the Domar Condition

Denote the government debt in a period (Period $t$ ) by $B_{t}$, and that in Period $t-1$ by $B_{t-1}$. Also, denote the fiscal spending and the tax in Period $t$ by $G_{t}$ and $T_{t}$. With

$$
C_{0}=(1+\rho) B_{t-1}
$$

(2) is rewritten as

$$
G_{t}-T_{t}=B_{t}-(1+\rho) B_{t-1}
$$

Let $Y_{t}$ and $Y_{t-1}$ be the national incomes in Periods $t$ and $t-1$. Then, since $B_{t}=\gamma B_{t-1}$,

$$
\frac{G_{t}-T_{t}}{Y_{t}}=\frac{B_{t}}{Y_{t}}-(1+\rho) \frac{B_{t-1}}{Y_{t}}=\frac{B_{t}}{Y_{t}}-\frac{1+\rho}{\gamma} \frac{B_{t-1}}{Y_{t-1}}
$$

If the effective interest rate $\rho$ is larger than the growth rate $\gamma-1$, and the budget is balanced, that is, $G_{t}=T_{t}$, we have

$$
\frac{B_{t}}{Y_{t}}=\frac{1+\rho}{\gamma} \frac{B_{t-1}}{Y_{t-1}}>\frac{B_{t-1}}{Y_{t-1}}
$$

This means that the debt to GDP ratio increases. Then, we need

$$
\rho<\gamma-1 \text {. }
$$

in order to prevent the debt to GDP ratio from increasing. This is a modified version of the Domar condition. If $\delta=1, \rho=r$.

As we have shown, however, the budget deficit (excluding interest payments) must be negative, that is, budget surplus is necessary to maintain full employment under economic growth with constant price if $\rho>\gamma-1$ (Proposition 2). The balanced budget when $\rho>\gamma-1$ induces inflation. Please see Section 3.3.

\section{Inflation by Excessive Budget Deficit and the Debt to GDP Ratio}

\subsection{Inflation by Excessive Budget Deficit}

Let $p>1$ be the price of goods in Period 1. Suppose that the nominal national income is $p Y_{f}$, and the nominal government expenditure is $G^{\prime} . C_{0}, I$ and $T$ do not change, and full employment is achieved. The inflation is not predicted. Then, we have

$$
p Y_{f}=\frac{1+\rho}{\gamma}\left[(1-\alpha)\left(Y_{f}-T\right)-I\right]+\alpha\left(p Y_{f}-T\right)+I+G^{\prime}
$$




\section{Ml Macrothink}

From this

$$
G^{\prime}-T=(1-\alpha)\left(p Y_{f}-T\right)-I-\frac{1+\rho}{\gamma}\left[(1-\alpha)\left(Y_{f}-T\right)-I\right]
$$

Comparing (2) and (4), we get

$$
G^{\prime}-T-(G-T)=(1-\alpha)(p-1) Y_{f} .
$$

Thus, $p>1$ when $G^{\prime}-T>G-T$. Therefore, we have shown the following result.

Proposition 4: The excessive budget deficit causes inflation (Note 3).

\subsection{When Inflation Is Predicted}

If the inflation is predicted,

$$
Y_{f}=\frac{1+\rho}{p \gamma}\left[(1-\alpha)\left(Y_{f}-T\right)-I\right]+\alpha\left(Y_{f}-T\right)+I+G
$$

Then, (4) should be rewritten as

$$
G-T=\frac{p \gamma-1-\rho}{p \gamma}\left[(1-\alpha)\left(Y_{f}-T\right)-I\right]
$$

or

$$
G-T+\frac{r}{p \gamma}\left[(1-\alpha)\left(Y_{f}-T\right)-I\right]=\frac{p \gamma+r-1-\rho}{p \gamma}\left[(1-\alpha)\left(Y_{f}-T\right)-I\right] .
$$

We suppose that in Period 1 the national income, the fiscal spending, the investment and the tax are $Y_{f}, G, I$ and $T$, and the price is one. In Period 0 they are $\frac{1}{p \gamma} Y_{f}, \frac{1}{p \gamma} G, \frac{1}{p \gamma} I, \frac{1}{p \gamma} T$ and $\frac{1}{p \gamma} p . p \gamma-1$ is the nominal growth rate. In this case, even if the interest rate $\rho$ is larger than the real growth rate $\gamma-1$, when it is smaller than the nominal growth rate $p \gamma-1$, we need positive budget deficit (excluding interest payments) to maintain full employment under economic growth.

Proposition 5: When inflation is predicted, we need positive budget deficit (excluding interest payments) to maintain full employment under economic growth even if the effective interest rate is larger than $\gamma-1$, so long as it is smaller than $p \gamma-1$.

When $\delta=1, \rho=r$. We have $\rho<r$ for $\delta<1$.

\subsection{Debt to GDP Ratio under Continued Inflation}

Let us calculate the long-run value of the debt to GDP ratio under continued inflation. Suppose full employment and inflation at a constant rate $p-1>0$, and we assume that inflation is predicted.

In Period 0, the nominal budget deficit is 


$$
\frac{1}{p \gamma}(G-T)=\frac{1}{p \gamma} B
$$

In Period 1, it is

$$
G-T+\frac{r}{p \gamma} B=\frac{p \gamma+r-1-\rho}{p \gamma} B .
$$

In Period 2, it is

$$
p \gamma(G-T)+r B=(p \gamma+r-1-\rho) B .
$$

Generally, in Period $n$ the nominal budget deficit is

$$
(p \gamma)^{n-1}(G-T)+r(p \gamma)^{n-2} B=(p \gamma)^{n-2}(p \gamma+r-1-\rho) B .
$$

Note that $G$ and $T$ denote the nominal fiscal spending and the nominal tax in Period 1. Since inflation is predicted, they increase at a constant rate $p \gamma-1$. The sum of the nominal budget deficit from Period 0 to $n$ is

$$
\sum_{k=1}^{n}(p \gamma)^{k-2}(p \gamma+r-1-\rho) B+\frac{1}{p \gamma} B=\left[\frac{(p \gamma)^{n}-1}{p \gamma-1}\right]\left(\frac{p \gamma+r-1-\rho}{p \gamma}\right) B+\frac{1}{p \gamma} B
$$

Since the national income in Period $n$ is $(p \gamma)^{n-1} Y_{f}$, the debt to GDP ratio in that period is

$$
\frac{\left[\frac{(p \gamma)^{n}-1}{p \gamma-1}\right]\left(\frac{p \gamma+r-1-\rho}{p \gamma}\right) B+\frac{1}{p \gamma} B}{(p \gamma)^{n-1} Y_{f}} .
$$

When $n \rightarrow \infty$, so long as $p \gamma-1>0$, that is, the nominal growth rate is positive, it converges to

$$
\left(\frac{p \gamma+r-1-\rho}{p \gamma-1}\right) \frac{B}{Y_{f}}=\left(\frac{p \gamma+r-1-\rho}{p \gamma-1}\right)\left[\frac{(1-\alpha)\left(Y_{f}-T\right)-I}{Y_{f}}\right] .
$$

Similar to (3), this has a finite value. We have shown the following result.

Proposition 6: Under full employment with continued inflation the debt to GDP ratio converges to a finite value so long as the nominal growth rate, $p \gamma-1$, is positive.

Note that this proposition also does not depend on the relationship between the interest rate and the nominal growth rate. They are included in $\frac{p \gamma+r-1-\rho}{p \gamma-1}$. However, it is finite when p $\gamma-1>0$.

3.4 Balanced Budget under Continued Inflation When the Effective Interest Rate Is Larger than the Growth Rate and the Domar Condition

Let $B_{t}, G_{t}$ and $T_{t}$ be the government debt, the fiscal spending and the tax in Period $t$, $B_{t-1}$ be the government debt in Period $t-1$. With

$$
B_{t-1}=\frac{1}{p \gamma} B_{t}
$$




\section{Al Macrothink}

(5) is rewritten as

$$
G_{t}-T_{t}=B_{t}-(1+r) \delta B_{t-1}=B_{t}-\frac{1+\rho}{p \gamma} B_{t}
$$

When the budget is balanced $\left(G_{t}=T_{t}\right)$, we obtain

$$
p \gamma=1+\rho, p \gamma-1=\rho, \text { and } p=\frac{1+\rho}{\gamma} .
$$

Thus, under the balanced budget the nominal growth rate $p \gamma-1$ equals the effective interest rate $\rho$ even if the real growth rate is smaller than $\rho$. In other words, the inflation rate $p-1$ is determined by the effective interest rate, and the real growth rate.

Let $Y_{t}$ and $Y_{t-1}$ be the nominal national incomes in Period $t$ and $t-1$. Then, since $Y_{t}=p \gamma Y_{t-1}$, we have

$$
\frac{G_{t}}{Y_{t}}-\frac{T_{t}}{Y_{t}}=\frac{B_{t}}{Y_{t}}-\frac{1+\rho}{p \gamma} \frac{B_{t-1}}{Y_{t-1}}
$$

Under the balanced budget $G_{t}=T_{t},(6)$ and (7) mean

$$
\frac{B_{t}}{Y_{t}}=\frac{B_{t-1}}{Y_{t-1}}
$$

Therefore, the debt to GDP ratio does not increase from Period $t-1$ to Period $t$. We have shown the following result.

Proposition 7: Under the balanced budget with inflation the effective interest rate equals the nominal growth rate, and the debt to GDP ratio does not increase even if the effective interest rate is larger than $\gamma-1$.

This means that the debt to GDP ratio never diverges to infinity.

\section{The Budget Deficit and the Savings by Consumers}

From (2)

$$
G-T+\frac{r}{\gamma}\left[(1-\alpha)\left(Y_{f}-T\right)-I\right]=\frac{\gamma+r-1-\rho}{\gamma}\left[(1-\alpha)\left(Y_{f}-T\right)-I\right]
$$

or

$$
G-T+\frac{r}{\gamma} B=\frac{\gamma+r-1-\rho}{\gamma} B
$$

These imply the following results.

Proposition 8: The budget deficit, including interest payments on government bonds, equals the difference between the savings of consumers in a period and the effective savings in the previous period. 


\section{1) Macrothink}

Let us consider generally. Let $\frac{1}{\gamma} \bar{Y}, \frac{1}{\gamma} \bar{T}$ be the actual real national income and the tax in the previous period (Period 0), $Y$ and $p$ be the actual real national income and the price in this period (Period 1). The effective savings in Period 0 equals

$$
\frac{1+\rho-r}{\gamma}[(1-\alpha)(\bar{Y}-\bar{T})-I]
$$

and the savings in Period 1 is

$$
(1-\alpha)(p Y-T)-I
$$

The price in Period 0 is normalized to 1 . From

$$
p Y=C_{0}+\alpha(p Y-T)+I+G,
$$

and

$$
C_{0}=(1+\rho) \frac{1}{\gamma}[(1-\alpha)(\bar{Y}-\bar{T})-I]
$$

the budget deficit, including interest payments on government bonds, in Period 1 is obtained as follows.

$G-T+\frac{r}{\gamma}[(1-\alpha)(\bar{Y}-\bar{T})-I]=(1-\alpha)(p Y-T)-I-\frac{1+\rho-r}{\gamma}[(1-\alpha)(\bar{Y}-T)-I]$.

Therefore, we get

Proposition 9: The result in Proposition 8 holds whether we have full employment or not, whether we have inflation or not.

\section{Conclusion}

The results reported in this note implies that the debt to GDP ratio never diverges to infinity even if not all savings of consumers in a generation is used for consumption of consumers in the next generation and the interest rate is larger than the growth rate so long as the real or nominal growth rate is positive, and always converges to a finite value accompanying inflation or not. This result is compatible with Lerner's functional finance theory (Lerner, 1943; Lerner, 1944) and the recently popular MMT argument (Mitchell, Wray, \& Watts, 2019; Wray, 2015; Kelton, 2020). Note that if fiscal spending is financed by money (seigniorage) instead of government bonds, interest payments are not necessary. Thus, by financing fiscal spending by money we can reduce the amount of interest payments, and can use fiscal spending for other purposes.

\section{Acknowledgments}

The author wish to thank the editor of this journal and the anonymous reviewers for comments on earlier version of this paper. This work was supported by JSPS KAKENHI Grant Number 18K01594 in Japan. 


\section{Mll Macrothink}

Issues in Social Science

ISSN 2329-521X

2022, Vol. 10, No. 1

\section{References}

Domar, E. D. (1944). The burden of debt and the national income. American Economic Review, 34, 798-827.

Kelton, S. (2020). The Deficit Myth: Modern Monetary Theory and the Birth of the People's Economy. Public Affairs.

Lerner, A. P. (1943). Functional finance and the federal debt. Social Research, 10, 38-51.

Lerner, A. P. (1944). The Economics of Control: Principles of Welfare Economics. Macmillan.

Mitchell, W., Wray, L. R., \& Watts, M. (2019). Macroeconomics. Red Globe Press.

Otaki, M. (2007). The dynamically extended Keynesian cross and the welfare-improving fiscal policy. Economics Letters, 96, 23-29. https://doi.org/10.1016/j.econlet.2006.12.005

Otaki, M. (2009). A welfare economics foundation for the full-employment policy. Economics Letters, 102, 1-3. https://doi.org/10.1016/j.econlet.2008.08.003

Otaki, M. (2015). Keynesian Economics and Price Theory: Re-orientation of a Theory of Monetary Economy. Springer. https://doi.org/10.1007/978-4-431-55345-8

Tanaka, Y. (2021). A brief rationale for MMT arguments. Issues in Social Science, 9, 1-8. https://doi.org/10.5296/iss.v9i2.19160

Tanaka, Y. (2022a). On budget deficit under economic growth: Towards a mathematical model of MMT. International Journal of Social Science Research, 10, 36-58. https://doi.org/10.5296/ijssr.v10i1

Tanaka, Y. (2022b). Debt to GDP ratio from the perspective of MMT. Business Management and Strategy, 13, 1-12. https://doi.org/10.5296/bms.v13i1.19353

Wray, L. R. (2015). Modern Money Theory: A Primer on Macroeconomics for Sovereign Monetary Systems (2nd ed.). Palgrave Macmillan.

Yoshino, N., \& Miyamoto, H. (2020). Revisiting the public debt stability condition: rethinking the Domar condition. ADBI Working Paper Series, No. 141, Asian Development Bank Institute. Retrieved from https://www.adb.org/sites/default/files/publication/606556/adbi-wp1141.pdf

\section{Appendix. Budget deficit due to unused savings}

In this appendix we consider a debt to GDP ratio about budget deficit due to unused savings and the role of inheritance tax to prevent the debt to GDP ratio from diverging indefinitely. If interest continues to be paid on savings that are not used for consumption, the ratio of their sum to GDP may diverge to infinity. In such a case, it shall be offset by means such as inheritance tax. 


\section{Macrothink}

The budget deficit in Period 2 shown in (4) does not include savings that are not used for consumption and interest payments on them. Let $\tau$ be the inheritance tax rate. Then, those in Period 2 with inheritance tax is

$$
(1+r-\tau)(1+r)(1-\delta) \frac{B}{\gamma}
$$

We assume that inheritance tax is imposed in Period 2 on Period 0 savings that are left unconsumed in Period 1. The same applies below. In Period 3

$$
(1+r-\tau)^{2}(1+r)(1-\delta) \frac{B}{\gamma}+(1+r-\tau)(1+r)(1-\delta) B
$$

In Period 4

$$
\begin{gathered}
(1+r-\tau)^{3}(1+r)(1-\delta) \frac{B}{\gamma}+(1+r-\tau)^{2}(1+r)(1-\delta) B \\
+(1+r-\tau)(1+r)(1-\delta) \gamma B
\end{gathered}
$$

Generally, in Period $n$ it is

$$
\begin{gathered}
(1+r-\tau)^{n-1}(1+r)(1-\delta) \frac{B}{\gamma}+(1+r-\tau)^{n-2}(1+r)(1-\delta) B+\cdots \\
+(1+r-\tau)^{2}(1+r)(1-\delta) \gamma^{n-4} B+(1+r-\tau)(1+r)(1-\delta) \gamma^{n-3} B \\
=(1+r)(1-\delta) B \sum_{k=1}^{n-1}(1+r-\tau)^{k} \gamma^{n-2-k}=(1+r)(1-\delta) \gamma^{n-2} B \sum_{k=1}^{n-1}\left(\frac{1+r-\tau}{\gamma}\right)^{k} \\
=(1+r)(1-\delta) \gamma^{n-2} \frac{\gamma}{1+r-\tau-\gamma}\left[\left(\frac{1+r-\tau}{\gamma}\right)^{n-1}-1\right] B .
\end{gathered}
$$

The ratio of this national debt to GDP in Period $n$ is

$$
\frac{(1+r)(1-\delta) \gamma^{n-2} \frac{\gamma}{1+r-\tau-\gamma}\left[\left(\frac{1+r-\tau}{\gamma}\right)^{n-1}-1\right] B}{\gamma^{n-1} Y_{f}}=\frac{(1+r)(1-\delta) \frac{\gamma}{1+r-\tau-\gamma}\left[\left(\frac{1+r-\tau}{\gamma}\right)^{n-1}-1\right] B}{\gamma Y_{f}}
$$

If

$$
\frac{1+r-\tau}{\gamma}<1
$$

or

$$
\gamma+\tau>1+r
$$

(10) converges to a finite value when $n \rightarrow \infty$. Therefore, an inheritance tax is needed to prevent the debt to GDP ratio from diverging indefinitely when $\gamma<1+r$. 
With continued inflation, we have

$$
\frac{(1+r)(1-\delta)(p \gamma)^{n-2} \frac{\gamma}{1+r-\tau-p \gamma}\left[\left(\frac{1+r-\tau}{p \gamma}\right)^{n-1}-1\right]_{B}}{(p \gamma)^{n-1} Y_{f}}=\frac{(1+r)(1-\delta) \frac{p \gamma}{1+r-\tau-p \gamma}\left[\left(\frac{1+r-\tau}{p \gamma}\right)^{n-1}-1\right] B}{p \gamma Y_{f}}
$$

If

$$
\frac{1+r-\tau}{p \gamma}<1
$$

or

$$
p \gamma+\tau>1+r
$$

(11) converges to a finite value when $n \rightarrow \infty$. An inheritance tax is needed to prevent the debt to GDP ratio from diverging indefinitely when $p \gamma<1+r$.

\section{Notes}

Note 1. This paper is an extension of Tanaka $(2021,2022 b)$ to a case where not all savings is used for consumption. In Tanaka (2022b) all savings is used for consumption.

Note 2. In other some studies, such as Tanaka (2022a), we considered an overlapping generations model with microeconomic foundations about behavior of consumers and firms under perfect competition or monopolistic competition according to, for example, Otaki (2007), Otaki (2009), Otaki (2015). In order to simplify the discussion in this note, we will skip the microeconomic foundation.

Note 3. A similar analysis can prove that tax cuts also lead to inflation.

\section{Copyright Disclaimer}

Copyright for this article is retained by the author(s), with first publication rights granted to the journal.

This is an open-access article distributed under the terms and conditions of the Creative Commons Attribution license (http://creativecommons.org/licenses/by/3.0/). 